Revista Educação e Políticas em Debate - v. 7, n. 3, p. 419-430, set./dez. 2018 - ISSN 2238-8346

\title{
Políticas públicas para a educação especial e inclusão no sistema educacional brasileiro
}

Public policies for special education and inclusion in the brazilian educational system

Politiques publiques pour l'education speciale et l'inclusion dans le systeme educatif bresilien

Josélia Maria da Silva Farias ${ }^{1}$

Universidade Federal do Piauí

Elaine Pontes Bezerra ${ }^{2}$

Universidade Federal do Piauí

Silvana Malusá ${ }^{3}$

Universidade Federal de Uberlândia

Resumo: O estudo objetiva analisar as principais políticas públicas voltadas à Educação Especial na perspectiva da educação inclusiva e seus reflexos no sistema educacional brasileiro, tendo como panorama as transformações ocorridas nas últimas décadas do século XX. Para tal empreendimento, recorremos a autores que discutem a temática, acrescidos a documentos legais que respaldam as políticas públicas para educação de forma geral e especificamente à educação especial na perspectiva inclusiva. A pesquisa mostrou que, embora as políticas públicas voltadas para educação inclusiva tenham avançado nos últimos anos, muitos desafios permanecem, pois a Legislação educacional brasileira garante o direito, mas na prática não há efetividade e eficácia na inclusão.

Palavras-chave: Políticas públicas. Educação. Inclusão.

Abstract: This study aims to analyze the main public policies focused on Special Education in the perspective of inclusive education and its repercussions in the Brazilian educational system, having as a panorama the transformations occurred in the last decades of the twentieth century. For this project, we have recourse to authors who discuss the theme, plus legal documents that support public policies for education in general and specifically to special education in an inclusive perspective. The research showed that although public policies focused on inclusive education have advanced in recent years, many challenges remain, since Brazilian educational legislation guarantees the right, but in practice there is no effectiveness and effectiveness in inclusion.

Keywords: Public policies. Education. Inclusion.

\footnotetext{
${ }^{1}$ Professora da Universidade Federal do Piauí (UFPI/CUMPP). Doutoranda DINTER Universidade Federal de Uberlândia - UFU. E-mail: joseliafarias2@gmail.com

${ }^{2}$ Professora da Universidade Federal do Piauí (UFPI/CMRV). Doutoranda DINTER Universidade Federal de Uberlândia - UFU.E-mail: elainepontes@hotmail.com

${ }^{3}$ Professora Associada IV da Universidade Federal de Uberlândia (UFU). Doutora e Pós-doutora em Educação. Coordenadora Pedagógica (DINTER/UFU/UFPI). Coordenadora do Grupo de Pesquisa "Desenvolvimento profissional e docência universitária: saberes e práticas educativas”. E-mail: silmalusa@yahoo.com.br
} 
Sommaire: Cette étude vise à analyser les principales politiques publiques axées sur l'éducation spéciale dans la perspective de l'éducation inclusive et ses répercussions dans le système éducatif brésilien, en ayant comme panorama les transformations survenues dans les dernières décennies du XXe siècle. Pour ce projet, nous avons recours à des auteurs qui discutent du thème, plus des documents juridiques qui appuient les politiques publiques pour l'éducation en général et spécifiquement pour l'éducation spéciale dans une perspective inclusive. La recherche a montré que bien que les politiques publiques axées sur l'éducation inclusive aient progressé ces dernières années, de nombreux défis subsistent, puisque la législation brésilienne en matière d'éducation garantit le droit, mais dans la pratique il n'y a pas d'efficacité et d'efficacité.

Mots-clés: Politiques publiques. Éducation. Iinclusion.

Recebido em: 25 de agosto de 2018 Aceito em: 15 de dezembro de 2018

\section{Introdução}

Para enfocar a política educacional brasileira se faz necessário manter uma atitude prudente e crítica acerca da temática, tendo plena consciência da sua amplitude e complexidade, motivo pelo qual não ensejamos abordá-la em seus múltiplos fatores determinantes, mas, tão somente elucidá-la enquanto ponto relevante para uma reflexão crítica no âmbito educativo. Nesse sentido, objetivamos analisar as principais políticas públicas voltadas à Educação Especial na perspectiva inclusiva na educação brasileira impressas nos documentos legais, bem como os seus reflexos nos sistemas de ensino.

As últimas décadas do século XX se caracterizaram por intensas transformações nos setores da economia, das instituições sociais, culturais e políticas que foram expressas nos processos de mundialização da economia e de reestruturação da divisão internacional do trabalho, da diminuição do papel do Estado, da desregulamentação dos mercados e de modificações no contexto político. Essas transformações que fazem parte do contexto neoliberal provocaram graves quadros de exclusão social, causando diversos desafios em todos os setores, dentre eles, o educacional.

$\mathrm{Na}$ atualidade, constata-se a precariedade da educação brasileira refletindo o insucesso escolar, sob a ótica de Puentes (2011, p.01):

São inúmeros os fatores externos e internos que tem contribuído para perpetuar essa situação de insucesso escolar que caracteriza a educação. Entre os mais conhecidos estão: a ausência de uma identidade; o sucateamento das instalações físicas da escola; a precariedade da formação profissional e das 
condições de trabalho dos professores; a falta de recursos financeiros; a ausência de um sistema eficiente de supervisão e fiscalização pedagógica; o baixo nível de expectativa do estado, a família, a escola, os professores e os próprios alunos em relação ao sucesso escolar; as concepções, modelos e práticas erradas de formação dos professores; as formas inapropriadas de organização didática dos processos de ensino e de aprendizagem presentes nas teorias pedagógicas sobre as quais se alicerçam os parâmetros curriculares nacionais; as práticas docentes ineficientes, tradicionais, dos professores em sala de aula, são fatores que prejudicam a qualidade das escolas e o desempenho acadêmico dos alunos.

Nesse sentido, a educação brasileira deve enfrentar o desafio de possibilitar o acesso, a permanência e o aprendizado a todos os indivíduos, independentemente de suas condições físicas, intelectuais, sociais, emocionais, linguísticas ou outras. As pessoas com deficiência, transtornos globais do desenvolvimento, altas habilidades e superdotação têm garantido o direito de usufruir de todos os bens sociais, no entanto, para que realmente haja a sua inserção no contexto escolar, são necessárias a definição e a execução de políticas públicas que tragam regulamentações, ações, orientações e que garantam investimentos para a Educação Especial numa perspectiva inclusiva. (Mendes, 2010).

É nesse contexto que situamos a relevância de refletirmos sobre políticas públicas para a educação especial e inclusão no sistema educacional brasileiro buscando compreender as políticas públicas de educação inclusiva presentes nos documentos legais identificando avanços e recuos bem como os seus reflexos no sistema educativo. Desse modo, tomaremos como base a compreensão de Educação Especial, os Movimentos Internacionais e Nacionais que serviram como referências de luta para que as pessoas com deficiências contassem com as mesmas condições e oportunidades educacionais oferecidas ao conjunto da população; os marcos legais que orientam as reformas bem como os seus reflexos no sistema educativo.

No contexto educativo brasileiro, em um período ainda recente, era comum, ao indagarmos aos professores da educação básica sobre o que compreendiam sobre educação especial, perceber a quase unanimidade da afirmação de que se tratava de um modelo de educação voltado para as crianças deficientes ou para aquelas que fracassam na escola, revelando assim nuances do que não se tratava de educação especial tendo em vista que nesse prisma, milhares de crianças entrariam nas estatísticas da Educação Especial mesmo sem apresentar qualquer tipo de deficiência, pois os alunos considerados normais também fracassam na escola.

Nesse caminho, a culpa pelo fracasso escolar recaía sobre a própria criança, tendo em vista que a sua deficiência o impossibilitava de aprender, pois a criança é que tinha que se adequar à escola e não o contrário. Para Prieto e Souza (2002): 
A luta deveria ser então pelo compromisso de viabilização de uma educação de qualidade para todos os indivíduos requerendo dos sistemas escolares a organização de uma diversidade de recursos visando atender aos alunos que, para se desenvolverem necessitam de auxílios ou serviços que normalmente não estão presentes na organização escolar.

Ou seja, agora é a escola que tem que se organizar para garantir a esses indivíduos os direitos que historicamente lhes vêm sendo negados dentro da sociedade, porquanto, na ótica de Batalla (2009):

A educação inclusiva se configura como paradigma emergente da educação especial trazendo como propostas a promoção da diversidade no ensino regular; a convivência com as diferenças; e a necessidade de mudanças nos sistemas de ensino para que criem as condições necessárias para a promoção da educação de qualidade para todos os alunos, para que sejam minimizadas ou até superadas a exclusão educacional e social a que são submetidas parcelas da população.

Para isso, é preciso a definição de políticas públicas que atendam as especificidades da Educação Especial. Entendemos políticas públicas como ações que nascem do contexto social, mas que perpassam pela esfera estatal como uma decisão de intervenção pública numa realidade social, seja para regulamentar administrativamente e/ou investir como resultado da dinâmica do jogo de forças entre grupos econômicos e políticos, classes sociais e demais organizações da sociedade civil que buscam nesse campo de disputas defenderem seus próprios interesses.

É importante salientar que a luta para que as pessoas com deficiência tenham assegurado o acesso, a permanência e a aprendizagem no ensino regular teve como referências movimentos internacionais e nacionais.

No âmbito internacional ressaltamos a Declaração Universal dos Direitos do Homem, que em 1948 afirmou que todo homem tem direito à instrução, o que foi reafirmado em 1975, com a proclamação da Declaração dos Direitos das Pessoas com Deficiência seguida da iniciativa da Organização das Nações Unidas - ONU - em iniciar a Década Internacional das Pessoas Portadoras de Deficiência (1981-1991), com a comemoração do Ano Internacional das Pessoas Deficientes, enfatizando questões sobre integração social e igualdade de direitos. Em 1990 a Conferência Mundial sobre Educação para Todos, realizada em Jomtiem na Tailândia, foi um grande marco para importantes mudanças nas políticas educacionais, configurando importantes reformas educativas, que se traduziram em medidas e ações políticas com vistas a um novo modelo de gestão escolar. 
Citamos o Relatório Delors produzido a partir dos desdobramentos da Conferência de Jomtiem, destacando a questão da responsabilidade do aluno pelo processo educativo, bem como a dimensão do respeito às diferenças.

Em 1994, a Declaração de Salamanca resultante da Conferência Mundial sobre necessidades especiais, ocorrida na Espanha em 1994, se tornou a principal referência no desenvolvimento das políticas educacionais no âmbito nacional e internacional. No que se refere à inclusão escolar a declaração de Salamanca afirma que o princípio fundamental da escola inclusiva é o de que todas as crianças devem aprender juntas, sempre que possível, independentemente de quaisquer dificuldades ou diferenças que elas possam ter. Desse modo, as escolas inclusivas deverão oferecer todas as condições necessárias que lhes assegurem uma educação efetiva. Prevê ainda, que as estruturas pedagógicas das escolas devem atender a todos os indivíduos, independentemente das suas condições físicas, intelectuais, sociais, linguísticas, superdotadas, étnicas, religiosas, bem como os indivíduos de outros grupos desvantajosos ou marginalizados, demanda, ainda que os Estados assegurem que a educação das pessoas deficientes seja parte integrante do sistema educacional.

Para Barretta e Canan (2012), a Declaração de Salamanca, além de contribuir para o fortalecimento da educação inclusiva e futuras modificações da política educacional, constitui uma reestruturação das instituições de educação voltadas para a filosofia inclusiva.

Ao referenciar as principais ações desenvolvidas no âmbito nacional, Prieto e Sousa (2002) retomam estudos realizados por Bieller (1990) que demonstram que, ao longo da história da educação brasileira, a Educação Especial foi passando por mudanças, sendo que na década de 50, surgiram as primeiras ações do governo, em nível nacional, voltadas para as pessoas com deficiência, através de campanhas sob a liderança de instituições privadas em conjunto com o governo federal. Entretanto, até a década de 70 as instituições privadas predominavam, sendo que, até esse período, as pessoas com deficiências não contavam com uma política educacional para o seu atendimento na rede pública. A criação do Centro Nacional de Educação Especial - CENESP- pelo MEC nessa mesma década foi um marco importante para a implementação de uma política nacional para a Educação Especial.

A partir de 1980, houve diversos movimentos de grupos que se organizaram com o objetivo de fazer valer seus direitos sociais que com a instituição do Ano Internacional das Pessoas com Deficiência, evento organizado pela ONU em 1981, houve uma grande mobilização dessa população, com a participação de várias áreas visando desencadear ações no âmbito nacional a exemplo do I Encontro Nacional de Entidades de Pessoas com Deficiência 
onde foi aprovada a pauta de lutas e criada a primeira entidade representativa de pessoas com deficiência, denominada Coalização Nacional, posteriormente organizada com a constituição de entidades nacionais por área de deficiência.

Em 1984 foram fundadas a Federação Brasileira de Entidades de Cegos - FEBEC -, a Organização Nacional de Deficientes Físicos - ONEDEF - e a Federação Nacional de Educação e Integração de surdos - FENEIS. Esses movimentos se expandiram tanto nacional como internacionalmente, ilustrando a luta que vem sendo travada para que sejam reconhecidos e atendidos os direitos dessa população, entre eles, o direito à educação, o que se evidencia na legislação vigente.

É importante ressaltar a presença do Banco Mundial que através de suas políticas estratégicas e suas intervenções em todos os níveis de ensino tem o privilégio de determinar os rumos da educação no país, tendo em vista que é uma das maiores agências de financiamento que tem inserido a educação de forma geral, na tendência mundial ou global de mercantilização dos direitos básicos a partir da adoção de políticas externas que se coadunam às diretrizes reformistas propostas ou impostas pelas implementações das políticas públicas, entre elas a educacional constituída pelo Banco Mundial, FMI, BIRD, dentre outros.

As agências internacionais, não apenas formulam condições para empréstimos, mas atuam junto aos Estados como implementadores de políticas educacionais. O Banco Mundial nas últimas décadas se transformou no organismo com maior visibilidade no cenário educativo mundial, ocupando espaços antes conferidos à UNESCO. (Barretta e Canan, 2012).

\section{Políticas de Educação Inclusiva: marcos legais}

A Constituição Federal de 1988 é a primeira dentre as constituições que estabelece explicitamente garantias especificamente voltadas aos portadores de deficiências. Tais dispositivos constam de três capítulos: Da seguridade social; Da educação, cultura e desporto e Da família, criança, adolescente e idoso, todos inclusos no título VIII, Da Ordem Social.

A Lei Maior determina que a educação é direito de todos e dever do Estado e da família, sendo que, no inciso III do art.208, assegura o atendimento educacional especializado as pessoas com deficiências, preferencialmente na rede regular de ensino. Seguindo essa compreensão, Prieto e Sousa (2002) advogam que:

[E]ssas e as demais determinações presentes no texto constitucional assegurando a educação enquanto direito subjetivo a todos os brasileiros permitiu que as políticas públicas voltadas para esse fim se tornassem mais 
presentes em diferentes espaços da legislação educacional da União, Estados e Municípios sendo que as novas constituições estaduais e as leis orgânicas municipais reproduziram ou ampliaram as referências á educação especial.

A Lei de Diretrizes e Bases da Educação Nacional, Lei Nº 9394/96 se refere à Educação Especial no capítulo V, determinando:

Art.58. Entende-se por Educação Especial a modalidade de educação escolar, oferecida preferencialmente na rede regular de ensino para educandos com deficiência, transtornos globais do desenvolvimento, altas habilidades ou superdotação.

No parágrafo primeiro, haverá, quando necessário, serviços de apoio especializado, na escola regular para atender às peculiaridades da clientela.

No parágrafo segundo o atendimento será feito em classes comuns de ensino regular sempre que em condições específicas dos alunos não for possível a sua integração.

No parágrafo terceiro determina que a oferta da educação especial dever do estado, será oferecida na faixa etária de zero a seis anos, durante a educação infantil.

Art.59. Os sistemas de ensino assegurarão aos educandos com deficiência, transtornos globais do desenvolvimento altas habilidades ou superdotação:

I - currículos, métodos, técnicas, recursos educativos e organização específicos para atender as suas necessidades.

II - terminalidade específica para aqueles que não puderem atingir o nível exigido para a conclusão do ensino fundamental e programas de aceleração para os superdotados.

III - Professores com especialização adequada em nível médio ou superior para o atendimento especializado, bem como professores do ensino regular capacitados para a integração nas classes comuns.

IV - educação especial para o trabalho, visando a sua efetiva integração na vida em sociedade, inclusive condições adequadas para os que não revelarem capacidade de inserção no trabalho competitivo mediante articulação com órgãos afins bem como para os que apresentam altas habilidades nas áreas artísticas, intelectual ou psicomotora.

V - acesso igualitário aos programas sociais suplementares disponíveis para os respectivos níveis do ensino regular.

Art.59-A. O poder público devera instituir cadastro nacional de alunos com altas habilidades e superdotação matriculados na educação básica ou superior, a fim de fomentar a execução de políticas públicas destinadas ao desenvolvimento pleno das potencialidades desse alunado. Lei 13.234/2015. 
Art.60 - Os órgãos normativos dos sistemas de ensino caracterizarão as instituições privadas sem fins lucrativos, especializadas e com atuação exclusiva em educação especial para fins de apoio técnico e financeiro pelo poder público.

A Resolução CNE/CEB n 2/2001 que institui as Diretrizes Curriculares Nacionais para a educação especial na educação básica reforçando as determinações presentes na LDB 9394/96 e orientando aos sistemas de ensino e as escolas a se organizarem para esse atendimento, assegurando as condições necessárias para uma educação de qualidade para todos. A proposta em questão conceitua a educação especial como a modalidade de educação escolar, isto é, entende-se um processo educacional definido por uma proposta pedagógica que assegure recursos e serviços educacionais, organizados institucionalmente para apoiar, complementar, suplementar e, em alguns casos substituir os serviços educacionais comuns, de modo a garantir a educação escolar e promover o desenvolvimento das potencialidades dos educandos que apresentam necessidades educacionais especiais, em todas as etapas e modalidades da educação básica.

A Resolução CNE/CEB n n 4/2009 em seu artigo primeiro determina que os sistemas de ensino devem matricular os alunos com deficiência, transtornos globais do desenvolvimento e altas habilidades/superdotação nas classes comuns do ensino regular e no atendimento educacional especializado (AEE), ofertado em salas de recursos multifuncionais ou em Centros de Atendimento Educacional Especializado da rede pública ou de instituições comunitárias, confessionais ou filantrópicas sem fins lucrativos.

Visando atender aos anseios da educação inclusiva, o governo federal vem implementando, nos últimos anos, políticas, planos, programas e ações no sentido de assegurar os direitos dos alunos com deficiência, transtornos globais do desenvolvimento, altas habilidades e superdotação no contexto educativo. Dada a amplitude e complexidade dessas ações, conforme ressaltado anteriormente, não temos a pretensão de abarcá-las em sua totalidade, desse modo, destacaremos alguns programas que consideramos mais representativas no panorama da Política Nacional de Educação Especial na Perspectiva da Educação Inclusiva.

A Política Nacional de Educação Especial na Perspectiva da Educação Inclusiva é um documento importante apresentado em 2008 pelo governo federal, através do Ministério da Educação, com o objetivo de constituir políticas públicas promotoras de uma educação de qualidade para todos os alunos. O documento apresenta um diagnóstico da educação especial, estabelece objetivos, define os alunos atendidos pela educação especial e traça diretrizes. A 
referida política tem como objetivo o acesso, a participação e a aprendizagem dos alunos com deficiência, transtornos globais do desenvolvimento e altas habilidades/ superdotação nas escolas regulares, orientando os sistemas de ensino para promover respostas às necessidades educacionais especiais (BRASIL, 2008).

Características:

- Orienta os sistemas de ensino para promover respostas as necessidades educativas especiais;

- Defende a inserção da educação especial na proposta pedagógica da escola regular;

- Define que o AEE não substitui a escolarização e sim complementa a formação dos alunos;

- O AEE deve ser realizado por profissionais com conhecimentos específicos;

- A educação especial perpassa todos os níveis e modalidades de ensino, disponibilizando recursos, serviços e orientações para a sua utilização nos processos de ensino.

a) Programa de Implantação de salas de recursos multifuncionais $\mathbf{- 2 0 0 7}$

- Segundo indicadores da SEESP-MEC no período de 2005 a 2011 o numero de escolas contemplados com o programa aumentou consideravelmente, sendo que nesse período 37.801 escolas foram beneficiadas. O programa disponibiliza as escolas equipamentos de informática, mobiliários, materiais pedagógicos e de acessibilidade para organizar os espaços de atendimento educacional especializado.

b) Programa Escola Acessível -Resolução N.27 de 27/07/12

- Destina recursos financeiros as escolas que atendam alunos especiais em classes comuns no ensino regular que tenham sido contempladas com as salas de recursos multifuncionais.

- Pesquisas do INEP/SEESP- mostram que do ano de 2008 a 2011, a quantidade de escolas atendidas chegou a 24.031 perfazendo um total de investimento na ordem de $\mathrm{R} \$ 203.381 .908,00$.

c) Programa de Formação Continuada de Professores na Educação Especial - (UABSECADI/MEC)

- Tem o objetivo de formar professores que atuam no atendimento educacional especializado, em salas de recursos multifincionais e professores do ensino regular para o desenvolvimento de práticas pedagógicas inclusivas

- Segundo dados do MEC-SEESP de 2007 a 2010 foram oferecidos 55 cursos de formação para 44.951 professores em 2.729 municípios. 


\section{d) Programa de Acompanhamento e Monitoramento do acesso e permanência na escola} das pessoas com deficiência beneficiários de prestação continuada da assistência social - Portaria Normativa Interministerial N.18 de 04/2007

- De acordo com o cruzamento dos dados do educacenso com os beneficiários da P.C.A.S. no ano de 2010 na faixa etária de 0 a 18 anos, foram atendidos 229.017 alunos que estavam matriculados no ensino regular, representando 52,61\% e 206.281 beneficiários que estavam fora da escola, ou seja 47,39\% do total.

\section{As matrículas na Educação Especial}

Os dados do censo escolar registram uma evolução nas matrículas da educação especial, passando de 337.326 em 1998 para 843.342 em 2013 expressando um crescimento de $150 \%$. Quanto a distribuição das matriculas por etapa de ensino em 2013:

- $\quad 59.959(7 \%)$ - educação infantil

- $614.390(73 \%)$ - ensino fundamental

- $\quad 48.889(6 \%)$ - ensino médio

- $\quad 118.047(13 \%)-\mathrm{EJA}$

- $2.357(1 \%)-\mathrm{EPT}$

O censo da Educação Superior registra que entre 2003 e 2012 o número de estudantes passou de 5.078 para 26.663 estudantes, representando um aumento de $425 \%$.

Nascimento (2015), ao analisar dados do Censo da Educação Básica do ano de 2010, no que refere ás matriculas, ao número de escolas beneficiadas com o Programa BPC, pelo Programa de Implantação das Salas de Recursos Multifuncionais, bem como do Programa de Formação Continuada de Professores na Educação Especial, infere que mais de 200.000 alunos com deficiências em idade escolar estão fora da escola; é preciso ampliar o número de estabelecimentos de Educação Especial com classes comuns e o número de escolas beneficiadas com os Programas de Salas de Recursos Multifuncionais e Escolas Acessiveis acrescidos á necessidade de ofertar um número maior de cursos de formação na área para os professores.

\section{Considerações finais}

O movimento mundial pela Educação inclusiva é uma ação política, cultural, social e pedagógica em defesa do direito de todos os estudantes de estarem juntos, aprendendo e participando sem nenhum tipo de discriminação e que deverá se refletir em todo o contexto 
social e não apenas nos espaços escolares. Entretanto, percebe-se que, apesar da Educação Especial ter alcançado uma boa organização sob o ponto de vista das disposições legais asseguradoras dos direitos às pessoas com deficiência, transtornos globais do desenvolvimento, altas habilidades/superdotação, o acesso à rede regular do ensino nos diversos níveis e modalidades - no cotidiano escolar esses direitos vêm sendo negados, pois apesar do acesso, os sistemas escolares ainda não oferecem todas as condições necessárias para que essa clientela obtenha sucesso em seu percurso educativo, demonstrando que não basta apenas garantir o acesso, é necessário realizar mudanças na organização das escolas para que as mesmas sejam capazes de incluir os alunos com necessidades educacionais especiais.

Portanto, reconhecemos que as políticas públicas são de extrema relevância para a implantação de um sistema educacional na perspectiva inclusiva, requerendo assim, mudanças profundas no sistema educacional, o que somente será possível se, articulada a essas políticas, houver a preocupação em estabelecer políticas de financiamento que assegurem a continuidade dessas ações e, principalmente se atenha à capacitação e valorização profissional dos trabalhadores da educação de forma geral, caso contrário a criação das escolas inclusivas no Brasil não passará de metafísica.

\section{Referências}

BRASIL. Censo Escolar. Brasília, MEC/INEP, 2010.

Constituição da República Federativa do Brasil. Brasília: Senado Federal, 1988.

Declaração de Salamanca e linha de ação sobre necessidades educativas especiais. Brasília: UNESCO, 1994.

Lei $n^{\circ} 9394$ de Dezembro de 1996. Estabelece as Diretrizes e Bases da Educação Nacional. Diário Oficial da União, Brasília, 1996.

Ministério da Educação. Secretaria de Educação Especial. Resolução CNE/CEB n ${ }^{\circ}$ 2, de 11 de Setembro de 2001. Diário Oficial da União, Brasília, 14 de Setembro de 2001. Seção $1 \mathrm{E}$, p.39-40.

Ministério da Educação. Secretaria de Educação Especial. Resolução CNE/CEB n ${ }^{\circ}$ 4 de 02 de Outubro de 2009. Diário Oficial da União. Brasília, 05 de Outubro de 2009, seção1, p.17.

Declaração Mundial Sobre Educação para Todos: Planos de ação para satisfazer as necessidades básicas de aprendizagem. UNESCO, Jomtiem/ Tailândia, 1990. 
MEC/SEESP. Política Nacional de Educação Especial. Brasília: MEC/SEESP, 1994.

. MEC/SEESP. Decreto $N^{o} 3298$ de 20 de Dezembro de 1999.

. MEC/SEESP. Lei no 10.436, de 24 de Abril de 2002. Dispõe sobre a Língua Brasileira de Sinais-LIBRAS e dá outras providências.

Política Nacional de Educação Especial na Perspectiva da Educação Inclusiva. 2008. Disponível em: <http/://portal.mec.gov.br/seesp/arquivos/pdf/politica.pdf $>$. Acesso em 20 de Junho de 2018.

Portaria Normativa Interministerial n ${ }^{\circ}$ 18. Programa BPC na Escola. 2007.

Portaria Interministerial $n^{\circ}$ 13. Programa de Implantação de Recursos Multifuncionais. Brasília: MEC. 2007.

Resolução n²7. Programa "Escola Acessível”. Brasília. MEC. 2012.

BARRETTA, E. M; CANAN, S. R. Políticas Públicas de Educação Inclusiva: avanços e recuos a partir dos documentos legais. IX ANPED SUL. Seminário de Pesquisa em Educação da Região Sul. 2012.

BATALlA, D. V. Política Nacional de Educação Especial na perspectiva da Educação Inclusiva brasileira. Fundamentos em Humanidades. Vol.19, N.1, 2009. Universidad Nacional de San Luis, Argentina.

DELORS, J. Educação - um tesouro a descobrir. São Paulo. Cortez- Brasília, DF: MEC: UNESCO, 2006.

FAQUIM, J. P. S.; PUENTES, R. V. Diferentes concepções de ensino: da didática do estimulo á didática do desenvolvimento. Revista RAC. p.1-11. Uberlândia-MG, 2011.

MENDES. E. G. Breve histórico da Educação Especial no Brasil. Revista Educacíon y Pedagogia. Vol. $22 \mathrm{~N}^{\circ}$ 57, Maio/ Agosto, 2010.

NASCIMENTO, S. V. Politicas públicas para educação especial na perspectiva da educação inclusiva no Brasil. XII Congresso Nacional de Educação- EDUCERE. PUCPR. 2015.

OLIVEIRA, R. P.; ADRIÃO, T.(orgs). Organização do ensino no Brasil: níveis e modalidades na Constituição Federal e na LDB, São Paulo. Xamã, 2002.

ORGANIZAÇÃO DAS NAÇÔES UNIDAS. Convenção sobre os Direitos das Pessoas com Deficiências. 2006. 